\title{
Facilitators and barriers to hypertension self-management in urban African Americans: perspectives of patients and family members
}

This article was published in the following Dove Press journal:

Patient Preference and Adherence

5 August 2013

Number of times this article has been viewed

\author{
Sarah J Flynn ${ }^{1,2}$ \\ Jessica M Ameling ${ }^{1,2}$ \\ Felicia Hill-Briggs ${ }^{1-3}$ \\ Jennifer L Wolff ${ }^{4,5}$ \\ Lee R Bone $\mathrm{R}^{1,3}$ \\ David M Levine ${ }^{1,4}$ \\ Debra L Roter ${ }^{3}$ \\ LaPricia Lewis-Boyer ${ }^{1,2}$ \\ Annette R Fisher ${ }^{6}$ \\ Leon Purnell ${ }^{6}$ \\ Patti L Ephraim ${ }^{2,7}$ \\ Jeffrey Barbers ${ }^{1,2}$ \\ Stephanie L Fitzpatrick ${ }^{1,2}$ \\ Michael C Albert ${ }^{1,8}$ \\ Lisa A Cooper ${ }^{1,2}$ \\ Peter J Fagan 9,10 \\ Destiny Martin' \\ Hema C Ramamurthi ${ }^{1,2}$ \\ L Ebony Boulware ${ }^{1,2,7}$
}

'Department of Medicine, Johns Hopkins University School of Medicine, Baltimore, MD, USA; ${ }^{2}$ Welch Center for Prevention, Epidemiology, and Clinical Research, Johns Hopkins Medical Institutions, Baltimore, MD, USA; ${ }^{3}$ Department of Health, Behavior, and Society, Johns Hopkins Bloomberg School of Public Health, Baltimore, MD, USA; ${ }^{4}$ Department of Health Policy and Management, Johns Hopkins Bloomberg School of Public Health, Baltimore, MD, USA; ${ }^{5}$ Division of Geriatric Medicine and Gerontology, Johns Hopkins University School of Medicine, Baltimore, MD, USA; ${ }^{6}$ Community and Provider Advisory Board, Johns Hopkins Center to Eliminate Cardiovascular Health Disparities, Baltimore, MD, USA; ${ }^{7}$ Department of Epidemiology, Johns Hopkins Bloomberg School of Public Health, Baltimore, MD, USA; ${ }^{8}$ Johns Hopkins Community Physicians, Johns Hopkins Medical Institutions, Baltimore, MD USA; ' ${ }^{\circ}$ epartment of Psychiatry and Behavioral Sciences, Johns Hopkins University School of Medicine, Baltimore, MD, USA; ${ }^{10}$ Johns Hopkins HealthCare LLC, Glen Burnie, MD, USA

Correspondence: L Ebony Boulware

Division of General Internal Medicine and Welch

Center for Prevention, Epidemiology and Clinical

Research, 2024 E Monument Street, Suite 2-600,

Johns Hopkins School of Medicine,

Baltimore, MD 21205, USA

Tel +l 4432874388

Fax + I 4109550476

Email lboulwa@jhmi.edu
Introduction: We aimed to inform the design of behavioral interventions by identifying patients' and their family members' perceived facilitators and barriers to hypertension selfmanagement.

Materials and methods: We conducted focus groups of African American patients with hypertension and their family members to elicit their views about factors influencing patients' hypertension self-management. We recruited African American patients with hypertension $(n=18)$ and their family members $(n=12)$ from an urban, community-based clinical practice in Baltimore, Maryland. We conducted four separate 90-minute focus groups among patients with controlled (one group) and uncontrolled (one group) hypertension, as well as their family members (two groups). Trained moderators used open-ended questions to assess participants' perceptions regarding patient, family, clinic, and community-level factors influencing patients' effective hypertension self-management.

Results: Patient participants identified several facilitators (including family members' support and positive relationships with doctors) and barriers (including competing health priorities, lack of knowledge about hypertension, and poor access to community resources) that influence their hypertension self-management. Family members also identified several facilitators (including their participation in patients' doctor's visits and discussions with patients' doctors outside of visits) and barriers (including their own limited health knowledge and patients' lack of motivation to sustain hypertension self-management behaviors) that affect their efforts to support patients' hypertension self-management.

Conclusion: African American patients with hypertension and their family members reported numerous patient, family, clinic, and community-level facilitators and barriers to patients' hypertension self-management. Patients' and their family members' views may help guide efforts to tailor behavioral interventions designed to improve hypertension self-management behaviors and hypertension control in minority populations.

Keywords: hypertension, patient perspective, qualitative research, health disparities

\section{Introduction}

Despite the existence of several efficacious pharmacologic and nonpharmacologic approaches to hypertension management, hypertension control throughout the United States is still inadequate, with less controlled blood pressure observed among African Americans compared to whites. ${ }^{1-4}$ Hypertension self-management behaviors including medication adherence, self-blood pressure monitoring, and lifestyle modifications involving diet, exercise, and tobacco are critical components of recommended hypertension treatment and have been associated with significant improvements in hypertension control. ${ }^{1,5-11}$ Compared to their white counterparts, African Americans with hypertension have been shown to have lower adherence to self-management 
behaviors. ${ }^{12-14}$ Studies assessing hypertensive patients' perceptions of factors influencing their self-management have demonstrated that barriers are multifactorial. ${ }^{15-19}$

Studies have shown that family members often play a crucial role in patients' hypertension self-management, including providing assistance with food selection and preparation, ${ }^{20,21}$ helping patients adhere to behavioral recommendations (for example, smoking cessation), ${ }^{22-24}$ and assisting patients with medication and medical appointment adherence. ${ }^{25-27}$ Family members may also play an important role in facilitating patient-provider discussions about hypertension care. ${ }^{28,29}$ Despite these findings, few studies have explored family members' perceptions of the facilitators and barriers they face in supporting patients' hypertension self-management.

Understanding African American patients' and family members' perceived facilitators and barriers to patients' hypertension self-management could provide insights into a range of important targets for interventions to improve African Americans' hypertension control, including patients' internally perceived barriers (for example, attitudes, beliefs, and confidence), family members' own needs in regard to supporting patients, and other aspects of patients' care and daily lives.

Tailoring intervention components to directly address patients' and family members' concerns may improve an intervention's effectiveness and sustainability. As part of the planning process for an interventional study designed to improve hypertension control among urban African Americans, we performed focus groups of African American patients with hypertension and their family members to better understand perceived facilitators and barriers to patients' hypertension self-management.

\section{Materials and methods Overall design}

We received funding from the National Heart, Lung, and Blood Institute to perform a randomized clinical trial to compare the effectiveness of tailored behavioral self-management interventions to improve hypertension control among urban African Americans. As part of the study's planning phase, we performed focus groups of African American patients and their family members to better understand their perceptions of factors influencing patients' self-management of hypertension. We recruited patients with hypertension and their family members from an academically affiliated, urban, community-based primary care clinic located in East Baltimore, Maryland. We hypothesized that patients with controlled and uncontrolled hypertension might have differing views about facilitators and barriers to hypertension selfmanagement. We further hypothesized that family members might have unique perspectives from patients on facilitators and barriers to hypertension self-management. We therefore performed separate focus groups of patients with controlled and uncontrolled hypertension (two groups of patients) and separate focus groups of their family members (two groups of family members).

\section{Participants}

We screened clinic electronic medical records to identify potentially eligible patient participants and included only English-speaking, African American adult patients with a diagnosis of hypertension. Using data obtained during the patients' clinic visits, we classified potential participants as having either controlled or uncontrolled hypertension based on the blood pressure value from their most recent clinic visit prior to recruitment, with uncontrolled hypertension defined according to the threshold of systolic blood pressure $\geq 140 \mathrm{mmHg}$ or diastolic blood pressure $\geq 90 \mathrm{mmHg}$. Once we recruited patient participants, we asked them to identify a family member who was involved in their care and who might also be interested in participating in a separate focus group session. We contacted patients' family members separately and invited them to participate in focus groups consisting only of family members.

\section{Focus group conduct}

African American moderators from the local community conducted each of the four separate focus groups involving patients with uncontrolled hypertension (one group), patients with controlled hypertension (one group), and their family members (two groups). Moderators included members of the study's Community and Provider Advisory Board who completed 6 hours of in-person training, as well as humansubjects certification prior to facilitating the sessions.

Moderators followed a structured guide and asked open-ended questions to assess patients' perceptions regarding factors influencing their hypertension selfmanagement, including the role of family members, the clinic itself, and community resources (Table 1). Moderators asked family members questions to ascertain the family members' views on patients' barriers to hypertension control, as well as to identify factors influencing their support of patients' hypertension self-management. Our development of the focus group questions was guided by our conceptual framework, which incorporated key aspects of social cog- 
Table I Patient and family member focus group questions assessing facilitators and barriers to patients' hypertension self-management

\begin{tabular}{|c|c|c|}
\hline Question topic & Patient questions & Family member questions \\
\hline Patient & $\begin{array}{l}\text { What needs to happen to help you manage your blood } \\
\text { pressure day to day? }\end{array}$ & $\begin{array}{l}\text { What is your view on some of the challenges that your } \\
\text { family member faces in caring for their high blood pressure? }\end{array}$ \\
\hline Family & $\begin{array}{l}\text { Tell me about the people in your life that you are close to } \\
\text { and who support and help you with your high blood pressure. } \\
\text { These may be family members, friends, and church members. }\end{array}$ & $\begin{array}{l}\text { How involved are you in your family member's treatment } \\
\text { for their high blood pressure specifically? }\end{array}$ \\
\hline Clinic & Tell me about your doctor's visits. How do they go? & $\begin{array}{l}\text { Tell me about the things you do to try to help your family } \\
\text { member at the doctor's. }\end{array}$ \\
\hline Community & $\begin{array}{l}\text { Tell me what is available to you outside of the doctor's office } \\
\text { in the community/neighborhood to help you take care of } \\
\text { your high blood pressure. }\end{array}$ & \\
\hline
\end{tabular}

nitive behavioral theory and the PRECEDE (Predisposing, Reinforcing, and Enabling Constructs in Educational Diagnosis and Evaluation)-PROCEED (Policy, Regulatory, and Organizational Constructs in Educational and Environmental Development) model. The framework held that patients' hypertension self-management behaviors are influenced by patient-, family-, clinic-, and community-level factors. ${ }^{30,31}$

The focus group sessions lasted for 90 minutes and were held at the clinic where the patients received their hypertension care. We audio-recorded and transcribed the focus group sessions verbatim for thematic qualitative analysis. At the beginning of the session, participants completed a brief questionnaire to assess their demographic information.

\section{Analytical strategy}

Three reviewers independently categorized participants' comments into themes and identified representative quotes to reflect each identified theme. Investigators collectively discussed their findings and reached mutual agreement on a final set of overarching themes emerging from each of the four focus groups.

\section{Ethical considerations}

The protocol for recruitment and conduct of the sessions was approved by the Institutional Review Board at Johns Hopkins University School of Medicine, Baltimore, MD, USA. All participants had knowledge that the sessions were audio recorded and they gave their oral informed consent to participate in the study. We reimbursed both patient and family member participants $\$ 50$ for their participation.

\section{Results}

\section{Study population}

A total of 30 patients and their family members participated in four separate focus groups (Table 2). Patient participants' ages ranged from 30 years to 82 years, and family member participants' ages ranged from 25 years to 63 years. The majority of participants had health insurance (93\%) and they had achieved at least a high school education (93\%). Patient participants with both controlled and uncontrolled hypertension had a self-reported mean hypertension duration of 19 years. Less than half (40\%) of family member participants of patients with controlled hypertension reported having hypertension themselves, compared to a majority (71\%) of family member participants of patients with uncontrolled hypertension.

\section{Patients' perceptions of facilitators and barriers to their hypertension self-management}

During the focus group sessions, patient participants discussed patient-, family-, clinic-, and community-level factors influencing their hypertension self-management (Table 3).

\section{Patient-level facilitators and barriers}

Patient participants shared that God was an important facilitator for their hypertension self-management. A patient participant with uncontrolled hypertension said, "I thank God for the way he takes care of me because I really don't have no one that I really can depend on" [Patient, uncontrolled hypertension].

Patient participants with controlled and uncontrolled hypertension discussed their personal barriers to incorporating and sustaining self-management behaviors into their daily routines, including taking their medications, quitting smoking, limiting stress, and reducing their dietary sodium intake. One patient with controlled hypertension described difficulties with smoking cessation:

I've tried the classes, I've tried [medicine], I've tried the patch, and they just don't work. But then, too, I have a very dysfunctional family, so that adds stress. The only time I want to smoke is in a stressful nature. [Patient, controlled hypertension] 
Table 2 Characteristics of focus group participants

\begin{tabular}{|c|c|c|c|c|}
\hline \multirow[t]{2}{*}{ Characteristics } & \multicolumn{2}{|c|}{ Controlled hypertension } & \multicolumn{2}{|c|}{ Uncontrolled hypertension } \\
\hline & $\begin{array}{l}\text { Patient } \\
(\mathbf{N}=\mathbf{8})\end{array}$ & $\begin{array}{l}\text { Family } \\
(N=5)\end{array}$ & $\begin{array}{l}\text { Patient } \\
(N=10)\end{array}$ & $\begin{array}{l}\text { Family } \\
(\mathbf{N}=7)\end{array}$ \\
\hline Age, mean (SD) & $61(14)$ & $50(10)$ & $60(14)$ & $43(17)$ \\
\hline Male sex, N (\%) & $3(38)$ & $2(40)$ & $3(30)$ & I (I4) \\
\hline High school graduate or greater, N (\%) & $8(100)$ & $5(100)$ & $8(80)$ & $7(100)$ \\
\hline \multicolumn{5}{|l|}{ Marital status } \\
\hline Married, N (\%) & $2(25)$ & $4(80)$ & $4(40)$ & $2(29)$ \\
\hline Not married, N (\%) & $6(75)$ & $\mathrm{I}(20)$ & $6(60)$ & $5(7 I)$ \\
\hline \multicolumn{5}{|l|}{ Health insurance } \\
\hline Insured, N (\%) & $8(100)$ & $4(80)$ & $10(100)$ & $6(86)$ \\
\hline Not insured, N (\%) & 0 & I (20) & 0 & I (I4) \\
\hline \multicolumn{5}{|l|}{ Family member relationship to patient, $\mathrm{n}(\%)$} \\
\hline Spouse/partner, N (\%) & - & $2(40)$ & - & I (14) \\
\hline Sibling, N (\%) & - & $2(40)$ & - & $\mathrm{I}(14)$ \\
\hline Parent, N (\%) & - & I (20) & - & 0 \\
\hline Adult child, N (\%) & - & 0 & - & $4(57)$ \\
\hline Friend, N (\%) & - & 0 & - & $\mathrm{I}(14)$ \\
\hline Self-reported HTN, N (\%) & $7(88)$ & $2(40)$ & $10(100)$ & $5(7 I)$ \\
\hline Years living with HTN, mean (SD) & $19(19)$ & $17(20)$ & $19(12)$ & $10(11)$ \\
\hline
\end{tabular}

Abbreviations: $\mathrm{N}$, number; SD, standard deviation; HTN, hypertension.

Patient participants from both sessions also often reported that managing their other nonhypertension comorbidities made it challenging for them to view self-management of their blood pressure as a high priority. A patient with uncontrolled hypertension shared:

I've had high blood pressure now since I think about late '88, maybe early '90s. I'm a diabetic. I'm 60 years old. I have high cholesterol. I have too much weight. My kidneys are failing, but I am on the donor list and so I'm going through that. My high blood pressure, like many of us, I didn't take it serious. I'm still fighting. [Patient, uncontrolled hypertension]

One patient participant with controlled hypertension described how managing her comorbid health sometimes led to confusion with her hypertension self-management:
So when I take my medicine for diabetes and I take my medicine for cholesterol and I also take the pain medication, sometimes I get confused whether I took [the blood pressure medication] or not. [Patient, controlled hypertension]

Patient participants with uncontrolled hypertension reported having only limited knowledge about their condition:

You know, I hear all the things, silent killer, called strokes

[...] but I can't grasp what [hypertension] is and why do I

have it. [Patient, uncontrolled hypertension]

This limited health knowledge and poor awareness of the complications associated with hypertension delayed patients' engagement in self-management behaviors. Some patient participants discussed how

Table 3 Patient participants' reports of patient-, family-, clinic-, and community-level facilitators and barriers to their hypertension self-management

\begin{tabular}{lll}
\hline Level & Facilitators & Barriers \\
\hline Patient & - God is an important support for patients. & - Difficulty incorporating and sustaining lifestyle changes. \\
& - Co-morbidities make controlling blood pressure a low priority. \\
Family & - Clinic reminder phone calls. & No comments. \\
Clinic & - Positive relationships with doctors. & - Long clinic wait times. \\
Community & - Community organizations sponsor health events. & - Insufficient access to fresh produce. \\
& & - Few places to exercise within neighborhoods. \\
& & $\bullet$ Lack of resources to check blood pressure between doctor's visits.
\end{tabular}


they began to seriously consider their condition only after experiencing a severe complication due to their hypertension. A patient participant with uncontrolled hypertension described:

The next thing I know, [the sodas] just kept falling out of my hands and I couldn't figure out why this was. And the next thing I know my daughter had took me to the hospital and she was telling the doctor that I'm bending my face up $[\ldots]$ and that was in 2000 that I had my stroke. But ever since then I've been working with a combination of my sugar, high blood pressure, cholesterol. [Patient, uncontrolled hypertension]

\section{Family-level facilitators and barriers}

Patient participants with controlled and uncontrolled hypertension reported that family members often facilitated their hypertension self-management and did not discuss any family-level barriers during the focus group sessions. They appreciated how family members helped prepare meals, attended medical visits, and reminded them to take their medication. One patient participant with controlled hypertension shared:

I have a family member that helps me, reminds me, and keeps me focused on my medicine, and it's my 13-yearold daughter. She stays on my case. I can't get mad and I have to take my medicine. She asks me every day before she goes to school, "Mom, did you take your medicine?" [Patient, controlled hypertension]

\section{Clinic-level facilitators and barriers}

Patient participants reported their hypertension selfmanagement was facilitated by calls from the clinic reminding them of upcoming appointments or the need for prescription refills. Most of the patient participants had been under the care of the same doctor for many years and reported that they trusted their doctors and felt comfortable asking questions during medical visits. Despite the experiences with their doctors, patient participants frequently reported long wait times at the clinic as a significant barrier to their hypertension self-management. One patient participant with uncontrolled hypertension said:

You sit back here, you're freezing cold. You got an appointment for 10:00 and its 11:30 and nobody's seen you. Okay, I'm gone. See you later. [Patient, uncontrolled hypertension]

\section{Community-level facilitators and barriers}

A few patient participants reported their hypertension self-management was facilitated by health-related events sponsored by local community organizations. One patient participant with controlled hypertension had enrolled in an educational seminar offered at a local hospital and another shared that her church occasionally organized health fairs with free blood pressure screenings. However, most of the participants reported that they were unaware of these community resources.

Many patient participants reported difficulties accessing fresh produce in their local community as a barrier to their hypertension self-management. Some patient participants shared that they were concerned about the poor quality and expensive cost of produce available in their neighborhoods. One patient with controlled hypertension described:

I live one block from the [...] market, and unfortunately, they have fresh fruit and meats and vegetables, but it's not of good quality. So instead of me walking one block to buy apples or whatever it is I need, I have to wait and get a ride and go to [a different] market. [Patient, controlled hypertension]

In addition to the limited availability of fresh fruits and vegetables, many patient participants also reported that they did not have safe or affordable places to exercise in their neighborhoods. Finally, some patient participants described being unable to check their blood pressure in between clinic visits due to a lack of resources in their communities. One patient participant with controlled hypertension said:

Give us all free blood pressure monitors where we can look at it and see because sometimes it's like we're 90 days in between and sometimes we can't afford those little meters that they have in the stores. [Patient, controlled hypertension]

\section{Family members' perceptions of facilitators and barriers to their support of patients' hypertension self-management}

Family member participants often reported that they were involved in helping patients adhere to their hypertension treatment plans. They reported that they reminded patients to take their medication, encouraged physical activity, attended patients' medical appointments, and helped prepare meals. 
One family member participant of a patient with controlled hypertension described:

I don't have high blood pressure but my mom does and I basically do all of her cooking. I monitor her medications. I take her back and forth to the doctor. I make sure she stays on a healthy diet. [Family member of patient with controlled hypertension]

During the focus group sessions, family member participants identified multilevel facilitators and barriers that influenced their support of patients' hypertension selfmanagement (Table 4).

\section{Patient-level facilitators and barriers}

Family member participants did not discuss patient-level facilitators during the focus groups sessions, but frequently reported that they perceived patients to have problems with personal motivation, which served as a barrier to their support of patients' hypertension self-management. Some family members felt that their attempts to encourage patients' self-management behaviors were significantly limited by the patients' reluctance to make lifestyle changes. A family member of a patient with uncontrolled hypertension shared:

My mom is like really stubborn, so she does what she wants to do. She does what she wants to do anyway, even though I fuss or whatever the case may be. [Family member of patient with uncontrolled hypertension]

Another family member participant of a patient with controlled hypertension described:

Sometimes it's hard, you try to make your spouse do the right thing and they do what they want to do. [Family member of patient with controlled hypertension]

\section{Family-level facilitators and barriers}

Some family member participants reported that they used the management of their own health conditions as a facilita- tor to encourage patients' hypertension self-management. One family member participant of a patient with controlled hypertension shared:

In my family my husband and I both have high blood pressure. So right now, well, we've been on medication for a couple of years $[\ldots]$ we make sure we take our medicine, and you know we cut back on salt, you know stuff that makes your blood pressure go up. [Family member of patient with controlled hypertension]

However, other family member participants reported their own health conditions posed a barrier to their involvement in patients' hypertension care. One family member participant of a patient with uncontrolled hypertension shared:

I too, have Crohn's disease and diverticular disease. I've been hospitalized myself [...] So it stresses me out sometimes and I end up in the hospital because I'm so stressed out trying to make sure that he's living, you know. [Family member of patient with uncontrolled hypertension]

Family member participants of patients with uncontrolled hypertension identified their own limited health knowledge about hypertension as a barrier to supporting patients' hypertension self-management. They felt they could better encourage patients if they had more education about hypertension. One family member of a patient with uncontrolled hypertension said:

I want to educate myself so I can help her. [Family member of patient with uncontrolled hypertension]

\section{Clinic-level facilitators and barriers}

Many family member participants reported that they accompanied patients to their medical appointments to facilitate patients' hypertension self-management. Some family members described their role in relaying health information about the patient to the doctor, asking questions, and taking notes during the appointments. These family members reported that attending patients' medical appointments helped them com-

Table 4 Family member participants' reports of patient-, family-, and clinic-level facilitators and barriers to their support of patients' hypertension self-management

\begin{tabular}{lll}
\hline Level* & Facilitators & Barriers \\
\hline Patient & No comments. & • Patients lack personal motivation for behavior change. \\
Family & - Family members use own health conditions to work together & • Family members have their own health conditions to manage. \\
& with patients. & • Family members have limited knowledge about hypertension. \\
Clinic & - Family members participate in patients' medical visits. & - Privacy concerns restrict some family members from \\
& - Some family members communicate with patients' doctors & attending patients' medical visits. \\
& outside of scheduled appointments. & \\
\hline
\end{tabular}

Note: *Questions about community-level facilitators and barriers were not asked during family focus group sessions. 
municate with patients' doctors. A family member participant of a patient with controlled hypertension shared:

It helps a lot because like she have like problems with her memories and whatever and it give me a chance to let the doctor know [what] she won't tell. She the type that won't tell everything. So it help me to be there to help tell it or I can hear what the doctor tell her because she won't come back to tell me. [Family member of patient with controlled hypertension]

A few family member participants also reported that they had communicated with patients' doctors outside of scheduled appointments, without patients' knowledge. Some family members explained that partnering with patients' doctors allowed them to better support patients' hypertension self-management behaviors. A family member of a patient with uncontrolled hypertension described:

And so one of the things I did was to call the doctor and ask them, could they educate him on the importance of not using outdated medicine [...]. When he came home [from the appointment], he was like, "Oh, my doctor said I had to throw it away." [Family member of patient with uncontrolled hypertension]

Privacy concerns restricted some family members from taking an active role in patients' medical visits. A family member participant described how he would not accompany his mother, who had uncontrolled hypertension, to her medical appointments:

I'd rather just sit in the lobby. I don't even know who her doctor is. I mean, whatever they're in there talking about, she can pretty much talk for herself. It must be confidential. She doesn't want me to know. [Family member of patient with uncontrolled hypertension]

\section{Discussion}

Patient participants identified facilitators to their hypertension self-management at the patient, family, clinic, and community levels (for example, God as an important source of support, family members encouraging lifestyle changes, positive relationships with doctors, and community organizations sponsoring health-related events). Patient participants also discussed barriers to their hypertension self-management at the patient, clinic, and community levels (for example, difficulty sustaining self-management behaviors, long wait times inhibiting engagement in care, and insufficient access to community resources). Family member participants described additional multilevel facilitators (for example, using their own health condition to encourage patients' behavior changes and participating in patients' medical visits) and barriers (for example, patients' lack of motivation to pursue behavior changes and their own limited health knowledge) that influenced their support of patients' hypertension self-care.

Our findings may inform efforts to tailor behavioral interventions to improve African Americans' hypertension self-management behaviors. The broad range of facilitators and barriers reported by patients at the patient, family, clinic, and community levels emphasize the importance of designing interventions that address multiple determinants of hypertension self-management and meet the specific needs of minority populations. Given that focus group participants reported difficulty managing other nonhypertensive comorbidities such as smoking and diabetes, and since they often did not prioritize their hypertension management, patients could benefit from interventions that simultaneously address multiple factors influencing patients' blood pressure control. Interventions that improve patients' health knowledge and problem-solving skills could also help patients incorporate and sustain the lifestyle changes necessary for hypertension control. Interventions incorporating patients' self-identified supports for self-management such as religion or spirituality may also improve patients' self-management behaviors.

In addition to highlighting the need for patients' sustained execution of hypertension self-management behaviors, our findings underscore the importance of developing strategies to support patients' efforts to engage with clinical practices and their communities as resources for care. Studies should not only address patients' specific personal facilitators and barriers, but they should also address external factors at the clinic and community levels. Interventions that enhance patients' relationships with providers, reduce clinic wait times, improve engagement with clinic outreach programs, and connect patients with community resources may improve patients' adherence to hypertension self-care behaviors.

Researchers have previously shown that family support can have a powerful influence on patients' long-term hypertension control and associated decreases in morbidity and mortality. ${ }^{27,32,33}$ In our focus groups, both patient and family member participants recognized family members as important facilitators to patients' hypertension self-care. We identified family members' perceived facilitators and barriers to supporting patients' hypertension management. Our findings suggest that encouraging family support may aid patients' hypertension self-management. They also suggest 
that family members may desire their own interventions. For instance, family members may benefit from increased health knowledge about hypertension and its associated comorbidities. Future interventions could jointly engage patients and family members to collaboratively identify ways family members can help patients sustain motivation for behavior change and achieve their hypertension selfmanagement goals. Future interventions could also encourage family members to take a participatory role during patients' clinic visits while still respecting patients' autonomy to make decisions and guide patient-provider discussions.

To our knowledge, this is one of the first studies to ask patients with controlled and uncontrolled hypertension and their family members to offer their independent perceptions about facilitators and barriers to hypertension self-management. Interestingly, the findings from the focus group sessions were similar, suggesting that controlled and uncontrolled hypertensive patients may frequently confront similar facilitators and barriers to hypertension control, and that their family members may encounter similar challenges to supporting patients' hypertension self-management. Based on these findings, additional efforts to significantly tailor interventions on the basis of patients' hypertension status, as either controlled or uncontrolled, may not be needed.

Our study has several potential limitations. First, our study population was limited to a select group of African American patients with hypertension and their family members living in a few neighborhoods in Baltimore, Maryland, and their experiences may not reflect the experiences of other hypertensive patients. Second, we did not confirm or validate patients' level of engagement in their self-management behaviors prior to their participation in the focus group sessions. Patients with controlled hypertension may or may not have better engagement than patients with uncontrolled hypertension in selfmanagement behaviors. Third, patients identified one family member to participate in family member focus groups, and it is possible that family members participating in the groups were more supportive of patients than family members not participating. It is also possible that other family members who did not participate in the sessions had different perspectives. Furthermore, our findings are similar to prior work in identifying potential barriers to hypertension self-management in African Americans and more diverse populations. ${ }^{18,19,34-40}$ Nonetheless, we believe our findings may help inform efforts to develop tailored interventions to improve hypertension self-management behaviors among similar urban African American populations in other studies. Future work is needed to help prioritize which factors may yield the most effective targets for interventions in order to improve hypertension control among urban minority populations.

\section{Conclusion}

Urban African American patients with hypertension identified patient-, family-, clinic-, and community-level facilitators and patient-, clinic-, and community-level barriers to their hypertension self-management. Family member participants identified family- and clinic-level facilitators and patient-, family-, and clinic-level barriers to their support of patients' hypertension self-management. Interventions designed to specifically address the multilevel determinants of hypertension self-management, as well as to engage family members in care, may strengthen efforts to improve hypertension control in urban minority populations.

\section{Acknowledgments}

This research was supported by a grant from the National Heart, Lung, and Blood Institute P50HL0105187.

\section{Disclosure}

The authors report no conflicts of interest in this work.

\section{References}

1. Wright JT Jr, Probstfield JL, Cushman WC, et al; ALLHAT Collaborative Research Group. ALLHAT findings revisited in the context of subsequent analyses, other trials, and meta-analyses. Arch Intern Med. 2009;169(9):832-842.

2. Fahey T, Schroeder K, Ebrahim S. Interventions used to improve control of blood pressure in patients with hypertension. Cochrane Database Syst Rev. 2006;(4):CD005182.

3. Hajjar I, Kotchen TA. Trends in prevalence, awareness, treatment, and control of hypertension in the United States, 1988-2000. JAMA. 2003;290(2):199-206.

4. Giles T, Aranda JM Jr, Suh DC, et al. Ethnic/racial variations in blood pressure awareness, treatment, and control. J Clin Hypertens (Greenwich). 2007;9(5):345-354.

5. Wassertheil-Smoller S, Shumaker S, Ockene J, et al. Depression and cardiovascular sequelae in postmenopausal women. The Women's Health Initiative (WHI). Arch Intern Med. 2004;164(3):289-298.

6. Chobanian AV, Bakris GL, Black HR, et al; National Heart, Lung, and Blood Institute Joint National Committee on Prevention, Detection, Evaluation, and Treatment of High Blood Pressure; National High Blood Pressure Education Program Coordinating Committee. The Seventh Report of the Joint National Committee on Prevention, Detection, Evaluation, and Treatment of High Blood Pressure: the JNC 7 report. JAMA. 2003;289(19):2560-2572.

7. Pickering TG, Miller NH, Ogedegbe G, Krakoff LR, Artinian NT, Goff D; American Heart Association; American Society of Hypertension; Preventive Cardiovascular Nurses Association. Call to action on use and reimbursement for home blood pressure monitoring: a joint scientific statement from the American Heart Association, American Society of Hypertension, and Preventive Cardiovascular Nurses Association. J Cardiovasc Nurs. 2008;23(4):299-323.

8. Elmer PJ, Obarzanek E, Vollmer WM, et al; PREMIER Collaborative Research Group. Effects of comprehensive lifestyle modification on diet, weight, physical fitness, and blood pressure control: 18-month results of a randomized trial. Ann Intern Med. 2006;144(7):485-495. 
9. Bosworth HB, Powers BJ, Oddone EZ. Patient self-management support: novel strategies in hypertension and heart disease. Cardiol Clin. 2010;28(4):655-663.

10. Dickinson HO, Mason JM, Nicolson DJ, et al. Lifestyle interventions to reduce raised blood pressure: a systematic review of randomized controlled trials. J Hypertens. 2006;24(2):215-233.

11. Glynn LG, Murphy AW, Smith SM, Schroeder K, Fahey T. Selfmonitoring and other non-pharmacological interventions to improve the management of hypertension in primary care: a systematic review. Br J Gen Pract. 2010;60(581):e476-e488.

12. Dickson M, Plauschinat CA. Racial differences in medication compliance and healthcare utilization among hypertensive Medicaid recipients: fixeddose vs free-combination treatment. Ethn Dis. 2008;18(2):204-209.

13. Shaya FT, Du D, Gbarayor CM, Frech-Tamas F, Lau H, Weir MR. Predictors of compliance with antihypertensive therapy in a high-risk medicaid population. J Natl Med Assoc. 2009;101(1):34-39.

14. Bosworth HB, Powers B, Grubber JM, et al. Racial differences in blood pressure control: potential explanatory factors. J Gen Intern Med. 2008;23(5):692-698.

15. Bokhour BG, Cohn ES, Cortés DE, et al. The role of patients' explanatory models and daily-lived experience in hypertension selfmanagement. J Gen Intern Med. 2012;27(12):1626-1634.

16. Mansyur CL, Pavlik VN, Hyman DJ, Taylor WC, Goodrick GK. Selfefficacy and barriers to multiple behavior change in low-income African Americans with hypertension. J Behav Med. 2013;36(1):75-85.

17. Peters RM, Aroian KJ, Flack JM. African American culture and hypertension prevention. Western J Nurs Res. 2006;28(7):831-854; discussion 855-863.

18. Lukoschek P. African Americans' beliefs and attitudes regarding hypertension and its treatment: a qualitative study. J Health Care Poor Underserved. 2003;14(4):566-587.

19. Ogedegbe G, Harrison M, Robbins L, Mancuso CA, Allegrante JP. Barriers and facilitators of medication adherence in hypertensive African Americans: a qualitative study. Ethn Dis. 2004;14(1):3-12.

20. Wilson DK, Ampey-Thornhill G. The role of gender and family support on dietary compliance in an African American adolescent hypertension prevention study. Ann Behav Med. 2001;23(1):59-67.

21. Schoenberg NE. The relationship between perceptions of social support and adherence to dietary recommendations among African-American elders with hypertension. Int J Aging Hum Dev. 1998;47(4):279-297.

22. Chandola T, Head J, Bartley M. Socio-demographic predictors of quitting smoking: how important are household factors? Addiction. 2004;99(6):770-777.

23. Park EW, Tudiver F, Schultz JK, Campbell T. Does enhancing partner support and interaction improve smoking cessation? A meta-analysis. Ann Fam Med. 2004;2(2):170-174.

24. Wagner J, Burg M, Sirois B. Social support and the transtheoretical model: relationship of social support to smoking cessation stage, decisional balance, process use, and temptation. Addict Behav. 2004;29(5): 1039-1043.

25. Trivedi RB, Ayotte B, Edelman D, Bosworth HB. The association of emotional well-being and marital status with treatment adherence among patients with hypertension. J Behav Med. 2008;31(6):489-497.
26. DiMatteo MR. Social support and patient adherence to medical treatment: a meta-analysis. Health Psychol. 2004;23(2):207-218.

27. Levine DM, Green LW, Deeds SG, Chwalow J, Russell RP, Finlay J. Health education for hypertensive patients. JAMA. 1979;241(16): 1700-1703.

28. Wolff JL, Roter DL. Family presence in routine medical visits: a metaanalytical review. Soc Sci Med. 2011;72(6):823-831.

29. Wolff JL, Roter DL. Hidden in plain sight: medical visit companions as a resource for vulnerable older adults. Arch Intern Med. 2008;168(13):1409-1415.

30. Gielen AC, McDonald EM. Using the PRECEDE-PROCEED planning model to apply to health behavior theories. In: Glanz K, Rimer BK, Lewis FM, editors. Using the Health Behavior and Health Education: Theory, Research, and Practice. 3rd ed. San Francisco, CA: Jossey-Bass; 2002:409-436.

31. Bandura A. Social Foundations of Thought and Actions: A Social Cognitive Theory. Englewood Cliffs, NJ: Prentice Hall; 1896.

32. Morisky DE, Levine DM, Green LW, Shapiro S, Russell RP, Smith CR. Five-year blood pressure control and mortality following health education for hypertensive patients. Am J Public Health. 1983;73(2):153-162.

33. Morisky DE, DeMuth NM, Field-Fass M, Green LW, Levine DM. Evaluation of family health education to build social support for long-term control of high blood pressure. Health Educ Q. 1985;12(1): 35-50.

34. Wexler R, Elton T, Pleister A, Feldman D. Barriers to blood pressure control as reported by African American patients. J Natl Med Assoc. 2009;101(6):597-603.

35. Cooper LA. A 41-year-old African American man with poorly controlled hypertension: review of patient and physician factors related to hypertension treatment adherence. JAMA. 2009;301(12):1260-1272.

36. Schlomann P, Schmitke J. Lay beliefs about hypertension: an interpretive synthesis of the qualitative research. J Am Acad Nurse Pract. 2007;19(7):358-367.

37. Bayliss EA, Steiner JF, Fernald DH, Crane LA, Main DS. Descriptions of barriers to self-care by persons with comorbid chronic diseases. Ann Fam Med. 2003;1(1):15-21.

38. Aroian KJ, Peters RM, Rudner N, Waser L. Hypertension prevention beliefs of Hispanics. J Transcult Nurs. 2012;23(2):134-142.

39. Turner BJ, Hollenbeak C, Weiner MG, Ten Have T, Roberts C. Barriers to adherence and hypertension control in a racially diverse representative sample of elderly primary care patients. Pharmacoepidemiol Drug Saf. 2009;18(8):672-681.

40. Russell BE, Gurrola E, Ndumele CD, et al; Community Health and Academic Medicine Partnership Project. Perspectives of non-Hispanic Black and Latino patients in Boston's urban community health centers on their experiences with diabetes and hypertension. J Gen Intern Med. 2010;25(6):504-509.
Patient Preference and Adherence

\section{Publish your work in this journal}

Patient Preference and Adherence is an international, peer-reviewed, open access journal focusing on the growing importance of patient preference and adherence throughout the therapeutic continuum. Patient satisfaction, acceptability, quality of life, compliance, persistence and their role in developing new therapeutic modalities and compounds to

\section{Dovepress}

optimize clinical outcomes for existing disease states are major areas of interest. This journal has been accepted for indexing on PubMed Central. The manuscript management system is completely online and includes a very quick and fair peer-review system. Visit http://www.dovepress.com/ testimonials.php to read real quotes from published authors. 